\title{
Improved Modeling of Three-Phase Transformer Analysis Based on Nonlinear B-H Curve and Taking Into Account Zero-sequence Flux
}

\author{
B. Kawkabani, J.-J. Simond \\ Swiss Federal Institute of Technology, Laboratory for Electrical Machines, Lausanne \\ EPFL-STI-ISE-LME, ELG Ecublens, CH - 1015 Lausanne, Switzerland \\ phone: (+4121) 6932680, fax: (+4121) 6932687, \\ e-mail: basile.kawkabani@epfl.ch
}

\section{Abstract}

The present paper deals with a new approach for the study of the steady - state and transient behaviour of threephase transformers. This approach based on magnetic equivalent circuit diagrams, takes into account the nonlinear B-H curve as well as zero-sequence flux. The nonlinear B-H curve is represented by a Fourier series, based on a set of measurement data. For the numerical simulations, two methods have been developed, by considering the total magnetic flux respectively the currents as state variables. Numerical results compared with test results and with FEM computations confirm the validity of the proposed approach.

\section{INTRODUCTION}

Traditionally in most of power system studies, the modeling of a three-phase transformer is reduced to its short-circuit impedance. The B-H curve introduced in some improved models and based on a set of measurement data, is approximated generally by several straight-line segments connecting the points of measurements. But apparently, such B-H curve obtained is not smooth at the joints of the segments, and the slopes of the straight lines, representing the permeability, are discontinuous at these joints. Moreover, in the set of differential equations considering the currents as state variables, one needs the expressions of the derivatives of the inductances versus the currents, which is impossible by using the above mentioned procedure.

For that reason in the present study, the nonlinear B-H curve (or U-I curve) is represented by a Fourier series technique [1], based on the set of measurement data. An analytical expression of a smooth $\mathrm{B}-\mathrm{H}$ curve connecting the discrete measurement points can be defined. By using a magnetic equivalent circuit-diagram representing the threephase transformer, all the self and mutual inductances can be expressed analytically in function of the magnetic reluctances of the cores. These inductances (and their derivatives) can be determined precisely using the predetermined series Fourier representation, and adapted at each integration step in the numerical simulations.

\section{FOURIER SERIES REPRESENTATION OF B-H CURVE (U=f(I) CURVE)}

A set of $N+1$ discrete measurement data $U_{n}$ and $I_{n}$ or $B_{n^{-}}$ $\mathrm{H}_{\mathrm{n}}$ of a three-phase transformer $(\mathrm{n}=0,1,2,3, \ldots \mathrm{N})$ is given. For the sake of making use of the Fourier series, a mirror image of this set of data is made about the $\mathrm{U}$ or $\mathrm{B}$ axis (Fig.1).

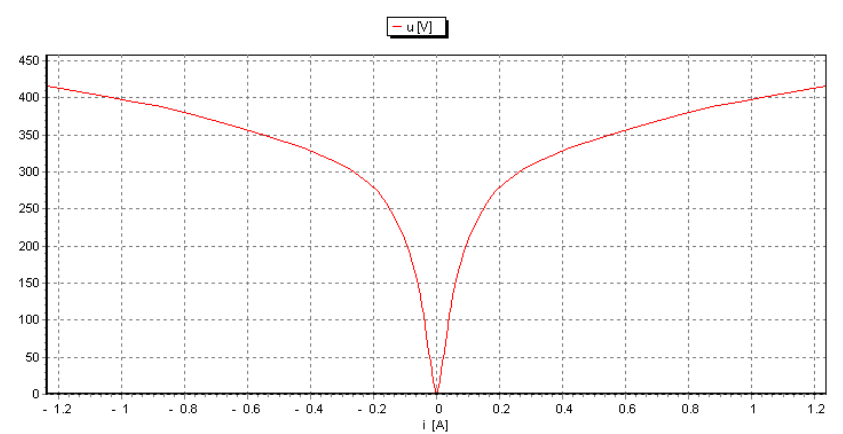

Figure 1. Set of measured data U-I and its mirror image.

One has:

$$
f(H)=a_{0}+\sum_{k=1}^{\infty} a_{k} \cdot \cos \left(\xi_{k} \cdot H\right)
$$

with:

$$
a_{0}=\frac{1}{H_{\max }} \cdot \sum_{n=1}^{N}\left[B_{n} \cdot\left(H_{n}-H_{n-1}\right)-\frac{1}{2} \cdot \alpha_{n} \cdot\left(H_{n}-H_{n-1}\right)^{2}\right]
$$

and

$$
a_{k}=\frac{2}{H_{\max }} \cdot \sum_{n=1}^{N}\left[\begin{array}{l}
\frac{\alpha_{n}}{\xi_{k}} \cdot \sin \left(\xi_{k} \cdot H_{n-1}\right) \cdot\left(H_{n}-H_{n-1}\right)+ \\
\frac{1}{\xi_{k}^{2}} \cdot \alpha_{n} \cdot\left(\cos \left(\xi_{k} \cdot H_{n}\right)-\cos \left(\xi_{k} \cdot H_{n-1}\right)\right)+ \\
\frac{B_{n}}{\xi_{k}} \cdot\left(\sin \left(\xi_{k} \cdot H_{n}\right)-\sin \left(\xi_{k} \cdot H_{n-1}\right)\right)
\end{array}\right]
$$

$H_{\text {max }}=H_{N}$

$\xi_{k}=\frac{k \cdot \pi}{H_{\max }}$ for the Kth term

$\alpha_{n}=\frac{B_{n}-B_{n-1}}{H_{n}-H_{n-1}}$

The calculated Fourier series curve and the measured curve are illustrated in Fig.2. The Fourier coefficients $a_{k}$ are computed once, then stored for the determination of $\mathrm{B}=\mathrm{f}(\mathrm{H})$ or $\mathrm{U}=\mathrm{f}(\mathrm{I})$ for all possible values of $\mathrm{H}$ or $\mathrm{I}$. The measured curve considered in this study corresponds to the line-to-line voltage in the primary, and to the current of the phase A of the primary winding. 


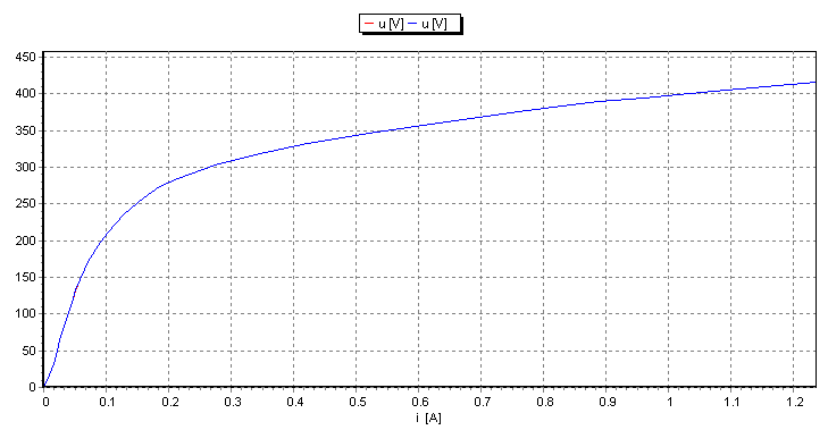

Figure 2. Calculated Fourier series curve and measured curve.

\section{NUMERICAL APPROACH}

Two methods have been developed for this approach. For both methods, the leakage inductances $\mathrm{L}_{\bullet 1}, \mathrm{~L}_{\bullet 2}$ of the primary and secondary windings, as well as the zerosequence inductances $\mathrm{L}_{\mathrm{o} 1}, \mathrm{~L}_{\mathrm{o} 2}$ are considered as constants. The first one considers the total magnetic flux as state variables. The corresponding set of six differential equations is given by:

$$
\begin{aligned}
& \frac{d[\psi]}{d t}=[B] \\
& {[B]=\left[\begin{array}{l}
u_{A B C}-R_{A B C} \cdot i_{A B C} \\
u_{a b c}-R_{a b c} \cdot i_{a b c}
\end{array}\right]}
\end{aligned}
$$

$\mathrm{R}_{\mathrm{ABC}}$ : resistances of the primary windings

$\mathrm{R}_{\mathrm{abc}}$ : resistances of the secondary windings

The total magnetic flux of different windings, including zero-sequence flux are given by:

$$
[\psi]=[L] \cdot[i]
$$

The self and mutual inductances are expressed in function of the magnetic reluctances $\mathrm{R}_{1 \mathrm{~T}}, \mathrm{R}_{2 \mathrm{~T}}, \mathrm{R}_{3 \mathrm{~T}}$ of the equivalent magnetic circuit-diagrams, with $\mathrm{N}_{1}, \mathrm{~N}_{2}$ the turns of the primary respectively secondary windings. For example, the magnetizing inductance of the primary winding A respectively the mutual inductance between the primary winding $\mathrm{A}$ and the secondary one $\mathrm{b}$ are given by:

$$
L_{h 1 A}=\frac{N_{1}^{2}}{R_{1 T}+\frac{R_{2 T} \cdot R_{3 T}}{R_{2 T}+R_{3 T}}}=\frac{N_{1}^{2} \cdot\left(R_{2 T}+R_{3 T}\right)}{R_{1 T} \cdot R_{2 T}+R_{1 T} \cdot R_{3 T}+R_{2 T} \cdot R_{3 T}}
$$

$$
L_{A b}=\frac{-N_{1} \cdot N_{2} \cdot R_{3 T}}{R_{1 T} \cdot R_{2 T}+R_{1 T} \cdot R_{3 T}+R_{2 T} \cdot R_{3 T}}
$$

Similar expressions are determined for all the inductances. The determination of the magnetic flux at each integration step permits to evaluate and adapt, by the $\mathrm{B}-\mathrm{H}$ curve, the different magnetic reluctances as well as different inductances.

Some numerical software package like SIMSEN [2] (http://simsen.epfl.ch) use essentially the currents as state variables. For this purpose, a second method has been developed. This one considers the following set of differential equations:

$$
[A] \cdot \frac{d[X]}{d t}=[B]
$$

with :

$$
[B]=\left[\begin{array}{l}
u_{A B C}-R_{A B C} \cdot i_{A B C} \\
u_{a b c}-R_{a b c} \cdot i_{a b c} \\
u_{A B C}-R_{A B C} \cdot i_{A B C}
\end{array}\right]
$$

$[X]^{T}=\left[\begin{array}{lllllllll}i A & i B & i C & \text { ia } & \text { ib } & \text { ic } & \psi A & \psi B & \psi C\end{array}\right]$

In this case, one needs 3 supplementary state variables $\psi_{A}, \psi_{B}, \psi_{C}$ and for the matrix [A] the expressions of all the inductances and especially all their derivatives versus the currents or the total flux (see Appendix). These expressions may be determined analytically by using the Fourier series relations mentioned before and adapted at each integration step.

\section{FEM COMPUTATIONS}

Based on the detailed knowledge of the geometry and the physical properties of different materials, 2D FEM field computations are performed for symmetrical and unsymmetrical loads in magnetodynamics, on a small transformer of $3 \mathrm{kVA}$ shown in Figure 3.

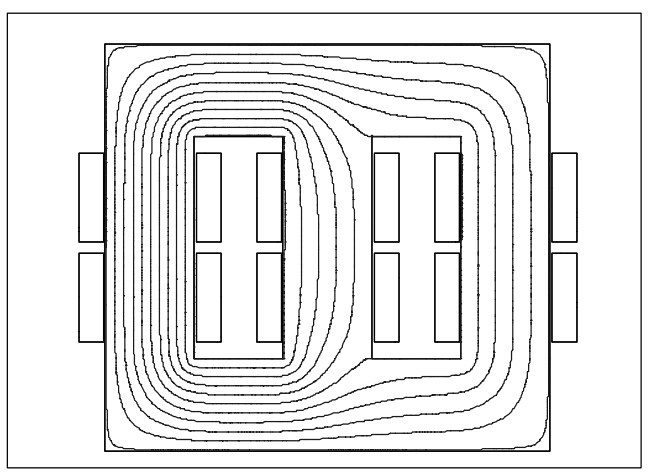

Figure 3: Transformer of $3 \mathrm{kVA}$ : Distribution of the magnetic field in the case of no-load.

The electric circuit related to different cases is shown in figure 4. One can notice the primary, secondary windings and the resistances of the load.

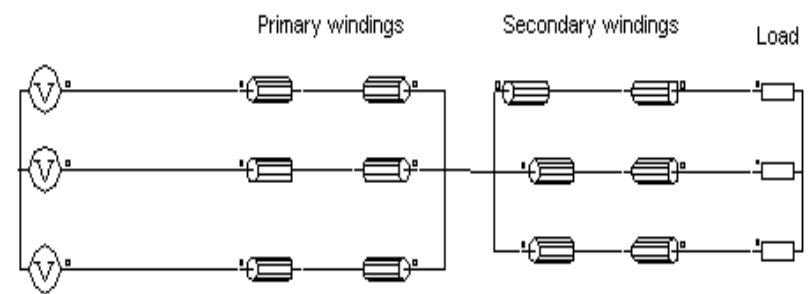

Figure 4: Electrical circuit related to FEM computations. 


\section{MEASUREMENTS. COMPARISON OF RESULTS}

A) Case of no-load for a transformer $\mathrm{Yy0}$ of $3 \mathrm{kVA}, 380$ $\mathrm{V} / 232 \mathrm{~V}, 50 \mathrm{~Hz}, \mathrm{ucc}=3.26 \%$.

Fig. 5 shows the computed primary currents given by the two numerical methods and relative to a small transformer of $3 \mathrm{kVA}$ in the case of no-load at rated voltage $380 \mathrm{~V}$.

Fig. 6 to 8 show respectively the measured respectively computed primary currents $\mathrm{iA}, \mathrm{iB}$ and $\mathrm{iC}$ relative to this case.

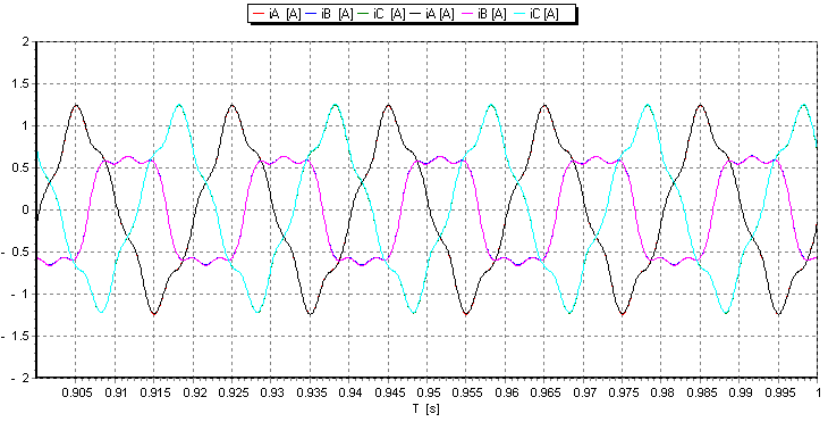

Figure 5. Computed primary currents given by the two numerical methods in the case of no-load.

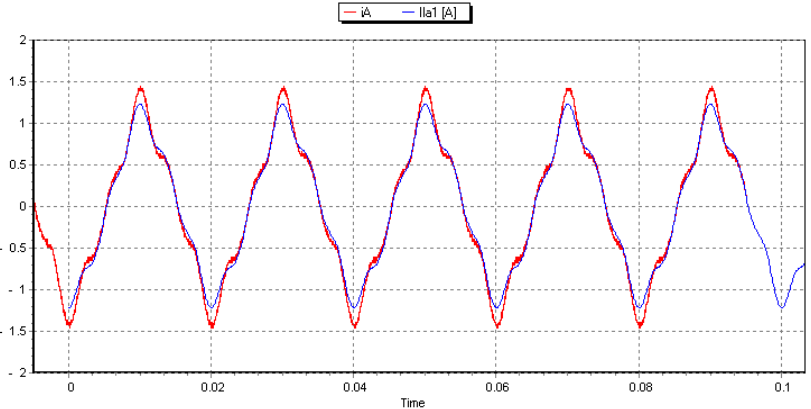

Figure 6. Computed and measured primary current iA in the case of no-load.

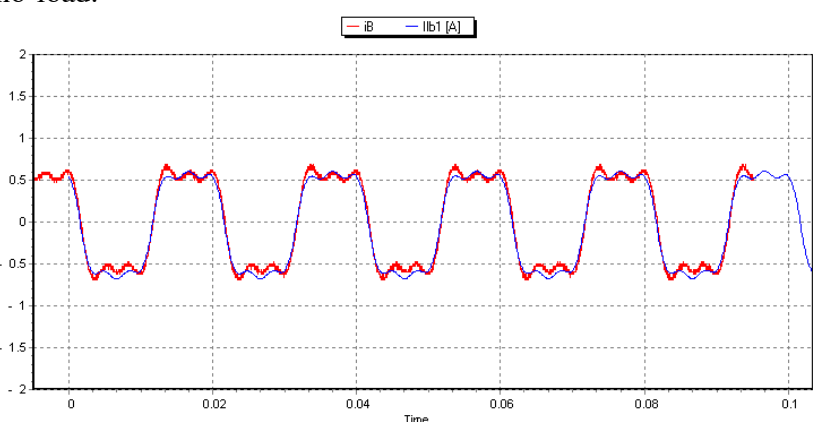

Figure 7. Computed and measured primary current $i B$ in the case of no-load.

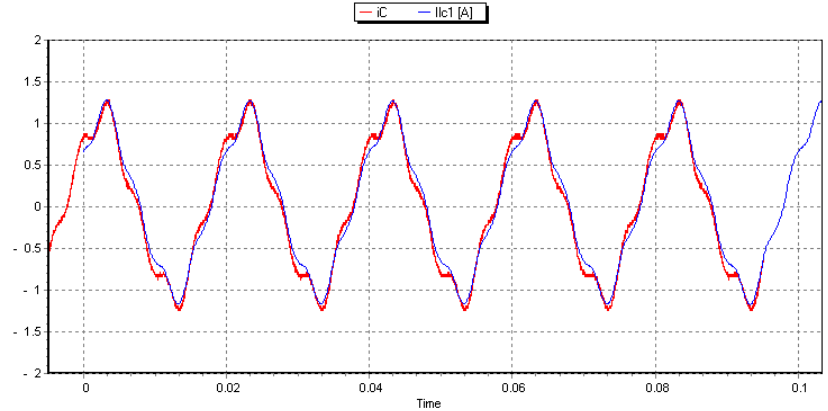

Figure 8. Computed and measured primary current iC in the case of no-load.
Table 1 shows results coming from different approaches in the case of no-load for a transformer Yy0, without connecting the neutrals in the primary and secondary sides.

TABLE I COMPARISON OF RESULTS CASE OF NO-LOAD FOR A TRANSFORMER YYO.

\begin{tabular}{|c|c|c|c|}
\hline & Test results & $\begin{array}{c}\text { Numerical } \\
\text { approaches }\end{array}$ & FEM approach \\
\hline & {$[\mathrm{A}]$} & {$[\mathrm{A}]$} & {$[\mathrm{A}]$} \\
\hline $\mathrm{I}_{\mathrm{A}}$ & 0.803 & 0.745 & 0.75 \\
\hline $\mathrm{I}_{\mathrm{B}}$ & 0.52 & 0.515 & 0.531 \\
\hline $\mathrm{I}_{\mathrm{C}}$ & 0.76 & 0.744 & 0.749 \\
\hline
\end{tabular}

B) Case of no-load for a transformer Dy5 of $3 \mathrm{kVA}, \mathrm{U}=$ $230 \mathrm{~V}$.

Fig. 9 to 11 show the measured respectively computed line primary currents relative to a coupling Dy5 in the case of no-load, under a voltage of 1.045 p.u.

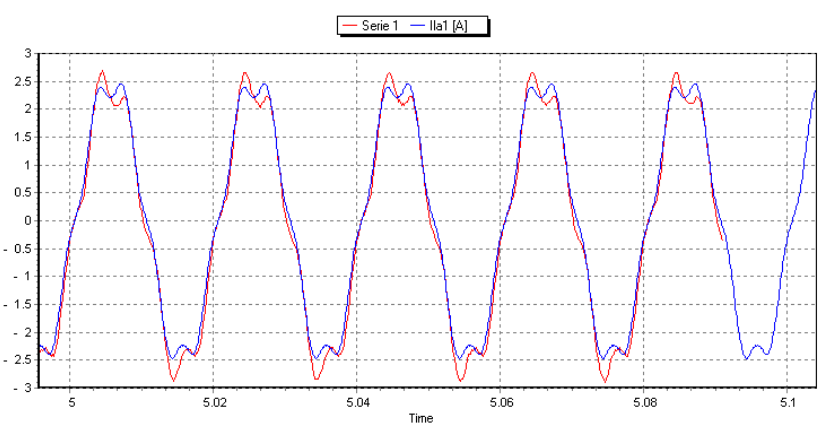

Figure 9. Computed and measured primary current ilA in the case of no-load.

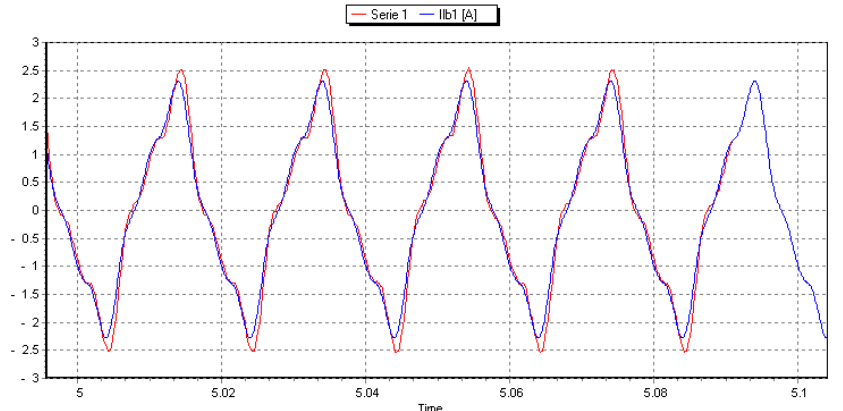

Figure 10. Computed and measured primary current ilB in the case of no-load.

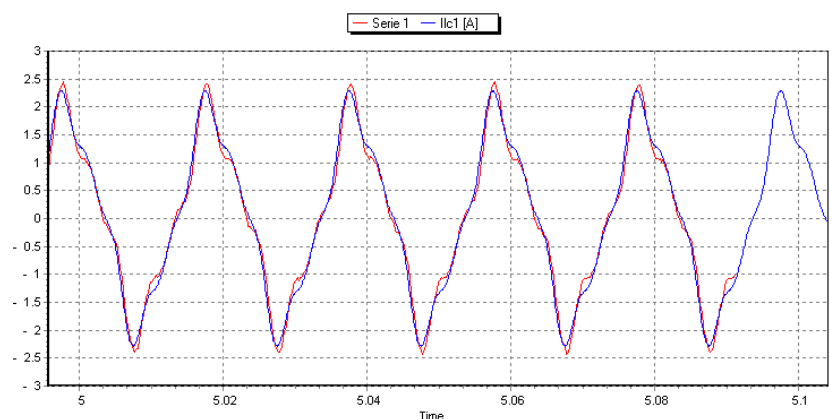

Figure 11. Computed and measured primary current ilC in the case of no-load. 
C) Case of a symmetrical load in the secondary, the primary supplied at its nominal voltage $380 \mathrm{~V}$, Yy0

Table 2 shows results coming from different approaches in the case of a symmetrical load connected to the secondary of the transformer $(\mathrm{Ra}=\mathrm{Rb}=\mathrm{Rc}=25 \Omega)$ under nominal voltage $\mathrm{U}_{\mathrm{N}}=380 \mathrm{~V}$, without connecting neutrals.

TABLE II COMPARISON OF RESULTS CASE OF SYMMETRICAL LOAD FOR A TRANSFORMER YYO.

\begin{tabular}{|c|c|c|c|}
\hline & Test results & $\begin{array}{c}\text { Numerical } \\
\text { approach }\end{array}$ & FEM approach \\
\hline & {$[\mathrm{A}]$} & {$[\mathrm{A}]$} & {$[\mathrm{A}]$} \\
\hline $\mathrm{I}_{\mathrm{A}}$ & 3.4 & 3.18 & 3.19 \\
\hline $\mathrm{I}_{\mathrm{B}}$ & 3.34 & 3.25 & 3.24 \\
\hline $\mathrm{I}_{\mathrm{C}}$ & 3.63 & 3.41 & 3.37 \\
\hline $\mathrm{I}_{\mathrm{a}}$ & 5.4 & 5.26 & 5.26 \\
\hline $\mathrm{I}_{\mathrm{b}}$ & 5.38 & 5.26 & 5.23 \\
\hline $\mathrm{I}_{\mathrm{c}}$ & 5.38 & 5.26 & 5.19 \\
\hline
\end{tabular}

D) Case of an unsymmetrical load in the secondary

Table 3 shows results coming from different approaches in the case of an unsymmetrical load connected to the secondary of the transformer $(\mathrm{Ra}=40.5 \Omega ; \mathrm{Rb}=$ $14.6 \Omega ; \mathrm{Rc}=39.15 \Omega ; 63.95 \%$ of unsymmetry) under nominal voltage $U_{N}=380 \mathrm{~V}$, with the neutral connected only in the secondary side. A measured zero-sequence inductance is taken into account in the secondary side $\mathrm{L}_{\mathrm{os}}=1.9 \mathrm{mH}$.

TABLE III COMPARISON OF RESULTS CASE OF A UNSYMMETRICAL LOAD FOR A TRANSFORMER YY0.

\begin{tabular}{|c|c|c|c|}
\hline & Test results & $\begin{array}{c}\text { Numerical } \\
\text { approach }\end{array}$ & FEM approach \\
\hline & {$[\mathrm{A}]$} & {$[\mathrm{A}]$} & {$[\mathrm{A}]$} \\
\hline $\mathrm{I}_{\mathrm{A}}$ & 2.62 & 2.50 & 2.55 \\
\hline $\mathrm{I}_{\mathrm{B}}$ & 4.46 & 4.33 & 4.30 \\
\hline $\mathrm{I}_{\mathrm{C}}$ & 3.41 & 3.2 & 3.15 \\
\hline $\mathrm{I}_{\mathrm{a}}$ & 3.2 & 3.2 & 3.22 \\
\hline $\mathrm{I}_{\mathrm{b}}$ & 9.17 & 8.89 & 8.82 \\
\hline $\mathrm{I}_{\mathrm{c}}$ & 3.42 & 3.45 & 3.39 \\
\hline
\end{tabular}

A very good agreement between results coming from different approaches and for different cases can be noticed (relative error less than $8 \%$ between different approaches). The present approach will be applied to a large transformer of distribution (1000 kVA, Dyn11, 18300/420V).

\section{CONCLUSIONS}

In the present paper, a new approach for the three-phase transformer analysis is described. This one based on equivalent magnetic circuit-diagrams takes into account the nonlinear B-H curve and zero-sequence flux. The B-H curve is represented by a Fourier series expression which gives a smooth B-H curve, and permits the analytical determination of all the inductances and their derivatives versus the currents. A very good agreement between results coming from different approaches is obtained.

\section{REFERENCES}

[1] Guanghao L., Xiao-Bang Xu, "Improved Modeling of the Nonlinear B-H Curve and Its application in Power Cable Analysis", IEEE Transactions on magnetics, vol. 38, No 4, pp. 1759-1763, July 2002.

[2] Simond J.-J.,Sapin A.,Kawkabani B.,Schafer D., Tu Xuan M., Willy B., "Optimized Design of Variable-Speed Drives and Electrical Networks", $7^{\text {th }}$ European Conference on Power Electronics and Applications EPE'97, Trondheim, Norway, September 1997.

[3] FLUX2D, version 7.60/6b, CEDRAT.

\section{APPENDIX}

\section{NUMERICAL APPROACH WITH THE CURRENTS AS STATE} VARIABLES

For example, the voltage equation relative to the primary $\mathrm{A}$ is given by:

$$
\begin{aligned}
& u_{A}=R_{A} \cdot i_{A}+\frac{d \psi_{A}}{d t}+\frac{d \psi_{o 1}}{d t}= \\
& R_{A} \cdot i_{A}+\left(L_{\sigma A}+L_{h 1 A}+L_{01}\right) \cdot \frac{d i_{A}}{d t}+\left(L_{A B}+L_{01}\right) \cdot \frac{d}{d t} i_{B} \\
& +\left(L_{A C}+L_{01}\right) \cdot \frac{d}{d t} i_{C}+L_{A a} \cdot \frac{d}{d t} i_{a}+L_{A b} \cdot \frac{d}{d t} i_{b}+ \\
& L_{A c} \cdot \frac{d}{d t} i_{c}+\frac{d \psi_{A}}{d t}\{\text { Vall }\}+\frac{d \psi_{B}}{d t}\{\text { Val } 2\}+\frac{d \psi_{C}}{d t}\{\text { Val }\}
\end{aligned}
$$

with :

$$
\begin{aligned}
& V a l 1=\frac{d R_{1 T}}{d \psi_{A}}\left(i_{A} \cdot \frac{\partial L_{h 1 A}}{\partial R_{1 T}}+i_{a} \cdot \frac{\partial L_{A a}}{\partial R_{1 T}}+i_{B} \cdot \frac{\partial L_{A B}}{\partial R_{1 T}}+\right. \\
& \left.i_{b} \cdot \frac{\partial L_{A b}}{\partial R_{1 T}}+i_{C} \cdot \frac{\partial L_{A C}}{\partial R_{1 T}}+i_{c} \cdot \frac{\partial L_{A c}}{\partial R_{1 T}}\right) \\
& V a l 2=\frac{d R_{2 T}}{d \psi_{B}}\left(i_{A} \cdot \frac{\partial L_{h 1 A}}{\partial R_{2 T}}+i_{a} \cdot \frac{\partial L_{A a}}{\partial R_{2 T}}+i_{B} \cdot \frac{\partial L_{A B}}{\partial R_{2 T}}+\right. \\
& \left.i_{b} \cdot \frac{\partial L_{A b}}{\partial R_{2 T}}+i_{C} \cdot \frac{\partial L_{A C}}{\partial R_{2 T}}+i_{c} \cdot \frac{\partial L_{A c}}{\partial R_{2 T}}\right) \\
& V a l 3=\frac{d R_{3 T}}{d \psi_{C}}\left(i_{A} \cdot \frac{\partial L_{h 1 A}}{\partial R_{3 T}}+i_{a} \cdot \frac{\partial L_{A a}}{\partial R_{3 T}}+i_{B} \cdot \frac{\partial L_{A B}}{\partial R_{3 T}}+\right. \\
& \left.i_{b} \cdot \frac{\partial L_{A b}}{\partial R_{3 T}}+i_{C} \cdot \frac{\partial L_{A C}}{\partial R_{3 T}}+i_{c} \cdot \frac{\partial L_{A c}}{\partial R_{3 T}}\right)
\end{aligned}
$$

and

$$
\frac{\partial L_{h 1 A}}{\partial R_{1 T}}=\frac{-N_{1}^{2} \cdot\left(R_{2 T}+R_{3 T}\right)^{2}}{\left(R_{1 T} \cdot R_{2 T}+R_{1 T} \cdot R_{3 T}+R_{2 T} \cdot R_{3 T}\right)^{2}}
$$

Similar expressions are established for all the partial derivatives of inductances versus the magnetic reluctances $\mathrm{R}_{1 \mathrm{~T}}, \mathrm{R}_{2 \mathrm{~T}}, \mathrm{R}_{3 \mathrm{~T}}$ of the cores. 